\title{
Thermally Sprayed Porous PEEK Coating for Biomedical Implants
}

\author{
Satish Tailor · Nitesh Vashishtha · Ankur Modi · S. C. Modi
}

Metallizing Equipment Company Pvt. Ltd., E-101, MIA Phase-II, Basni, Jodhpur, India.

\begin{abstract}
The present study reports the novel results of microstructural and mechanical properties of highly porous Polyetheretherketone (PEEK) coating. PEEK is already considered as a material for biomedical implants. A new kind of approach is proposed for manufacturing of highly porous PEEK coating on a dense PEEK coating for orthopedic implants and successfully implemented to create novel biomimetic porous PEEK coating by means of thermal spray process. To imitate the structure of natural bone, as-sprayed top PEEK coating has porosity of more than $60 \%$ vol. and pore sizes of 30-80 $\mu \mathrm{m}$. Mechanical results of dense PEEK coating show that PEEK coating exhibited good strength, hardness (20 HV0.1) and good bonding strength (15 MPa) with the metal substrate. Thermal sprayed porous PEEK coating that can be used for future implants instead of plasma sprayed titanium coating on dense PEEK implants because porous PEEK improves the bone-implant interface joining compared to plasma-sprayed titanium coating on PEEK. (c) 2019 JTSE and INScienceIN. All rights reserved
\end{abstract}

\section{Introduction}

Polyetheretherketone (PEEK) is a high strength semicrystalline thermoplastic and is one of the most common materials used for load-bearing orthopedic implants, particularly in spine due to its radiolucency and favorable mechanical properties [1-2]. In 1990s, the uses of PEEK implants have been considered worldwide owing to its radiolucent structure with high flexibility and chemical resistivity in comparison to metallic implants. These characteristics of PEEK material are equal to bone material make easier to design of biomedical implants with minimum stress shielding [3]. The potential applications of PEEK material are bone replacement, dental implant, craniomaxillo facial and cartilage replacement. Less osseointegration and bioactivity led to clinical failure of conventional dense PEEK implants as reported earlier [47]. To ascertain the better results of PEEK implants, significantly number of research investigations is required. Some recent studies suggests that porous PEEK structured implant possessed good osseo-conductive properties which is promoting the use of PEEK implants instead of titanium implants. Although possible potentials of PEEK implant are still a debating issue. Smooth surface of titanium and other bio materials implants could cause limited osseointegration between an implant and bone [8-12] Conventional dense PEEK implants also have a smooth surface because of injection molding process. Therefore, porous PEEK coating on implant would be a viable solution in alternate to porous titanium coating on PEEK implants. Using porous structured PEEK implant can be result into the enhanced mechanical interlocking by in growth of bone tissues through the pores present as compared to roughened surface. Osseointegration is affected by the surface finish and chemical composition and their proportionally contributions but still appallingly known [13-14].

Plasma sprayed porous titanium coating on PEEK implants improves osseointegration. Pure titanium coating with thickness $100-250 \mu \mathrm{m}$ is widely adopted for clinical implants [4, 15-16]. Wear down of these coatings over time resulted into wear debris formation and under further movement of implant led to damage of bone tissues and aseptic loosening [16-19]. Therefore, plasma sprayed titanium coating could revamp PEEK implants on the stake of feasibility and affinity with PEEK material.

Now-a-days, the efforts are being made and focused on fabrication of porous structure of PEEK and of other biocompatible polymers in order to reconstruct expanded bone defects [20-22]. Another clinically-available alternative to smooth PEEK is porous PEEK. A few recent studies has demonstrated that porous PEEK structure can withstand relevant physiological and intraoperative loads, facilitate cellular proliferation and osteogenic differentiation, and enhance PEEK osseointegration in preliminary animal studies and clinical case reports [2326].

A novel approach is proposed for manufacturing of highly porous PEEK coating by means of thermal spray process. As per available literature, PEEK is already has been considered for biomedical application due to its radiolucency, bio compatibility and favorable mechanical properties; therefore the present study reports only the results and findings in the fabrication of tailored highly porous PEEK coating to facilitate bone in growth and preserve PEEK's favorable medical imaging properties.

\section{Experimental \\ Materials \& Methods}

PEEK powder ("Victrex 150UF10", UK) is used as feedstock and pure titanium plats were used as substrates material. The coatings of porous PEEK were deposited at R\&D facility, MEC Jodhpur with new flame spray hardware (specially designed and developed for polymers) onto titanium substrates of dimensions $80 \times 50 \times 3 \mathrm{~mm}^{3}$. To achieve a uniform coating thickness and consistent coating properties the coating process was carried out in a thermal spray booth using a robot. Prior to spraying substrates were cleaned with acetone for 5 minutes and grit blasted in 
order to increase the surface roughness, so that it could improve the adhesion strength of the coating to the substrate. To deposit the PEEK coating spray parameters are listed in Table 1.

Table 1: Spray parameters for PEEK coating

\begin{tabular}{cc}
\hline Parameter & Value \\
\hline Fuel & $30 \mathrm{psi}$ \\
Oxygen & $40 \mathrm{psi}$ \\
Air & $40 \mathrm{psi}$ \\
Spray Distance & $12 \mathrm{inch}$ \\
Powder feed rate & $25 \mathrm{gm} / \mathrm{min}$ \\
\hline
\end{tabular}

\section{Coating characterizations and testing}

As-sprayed coatings were tested and characterized in the $R \& D$ laboratory of MEC India. Cross-sections of the samples were examined under the Scanning Electron Microscope (Carl ZEISS Evo18, UK) equipped with Backscatter electron detector (BSC) and EDS analysis (Oxford Instruments, United Kingdom). Software "ImageJ" was used to distract data on volume porosity, pore and interconnections sizes from BSE images. Porous PEEK cross-sections were manually contoured tightly to the pores to minimize inclusion of non-porous volume. Microcomputed tomography $(\mu \mathrm{CT})$ was used to characterize the porous structure of porous PEEK samples. Scans were performed using a $17.2 \mu \mathrm{m}$ voxel size, $55 \mathrm{kVp} 17$ tube voltage, $200 \mu \mathrm{A}$ tube current, and $215 \mathrm{msec}$ integration time ( $\mu$ CT 50, Scanco Medical, Brüttisellen, Switzerland).

The microhardness was examined with a Vickers micro indenture (SHIMADZU HMV-G-21ST, Japan) as per ASTME384 under a load of $100 \mathrm{~g}$ (HV0.1) and fifteen measurements were taken on the coated sample. The tensile strength of the coating was tested using INSTRON
Digital Tensile Testing Machine (Model: 5969 USA) according to ASTM-C633. The adhesion strength of the coating was tested by pull-off strength of coatings using portable adhesion test as per ASTM D 4541. In addition compression mechanical testing (ISO 604:2002) was performed using INSTRON Digital Tensile Testing Machine (Model: 5969 USA).

\section{Results and Discussion}

Microstructures of porous PEEK coating are shown in Figure 1. Figure 1a and Fig. 1b-d corresponds to crosssection and as-sprayed top surface of the porous PEEK coating, respectively. The porosity level in the coating is found to be more than 60 vol. \%, as shown in Fig. 1b-d, more than $90 \%$ of pores are in the range of 30-70 $\mu \mathrm{m}$ and in depth as well. As per previous study [10], such porosity is preferred for the colonization with osteoblasts. In order to increase adhesion strength of the final coating, a dense PEEK coating of 40 micron was deposited (Figure 1e) on the substrate prior to fabricate porous PEEK coating of 150 micron. Combination of dense layer and porous peek layers are suitable in bone reconstructive surgery to create tailored scaffolds having adequate mechanical properties. It was observed and confirmed that no delamination, microcracks or fusion defects are viewed between the layers. Thus, the proposed method is efficient to form a bilayer structure, simulating cortical and trabecular bone implants. Now-a-days researchers are focused on fabrication of porous peek coatings for future bone implants, having structure like different bone tissues and having considerable mechanical properties.

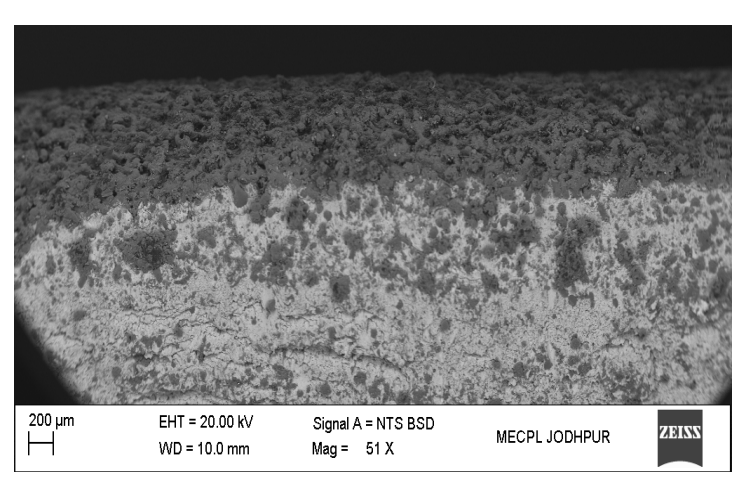

(a)

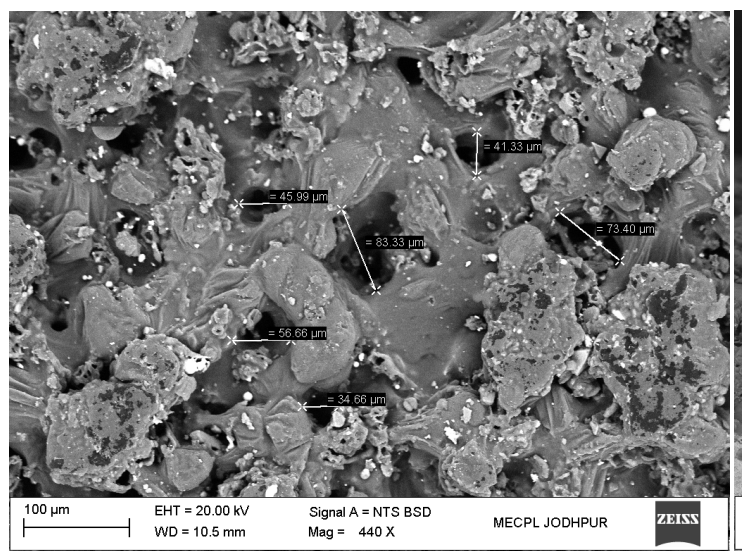

(c)

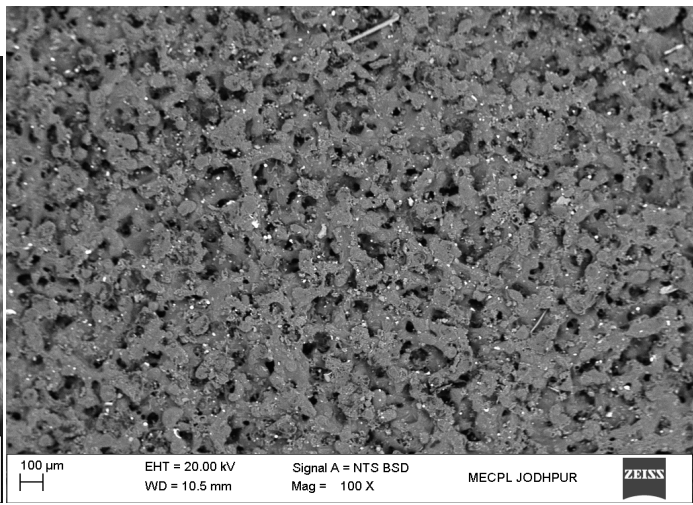

(b)

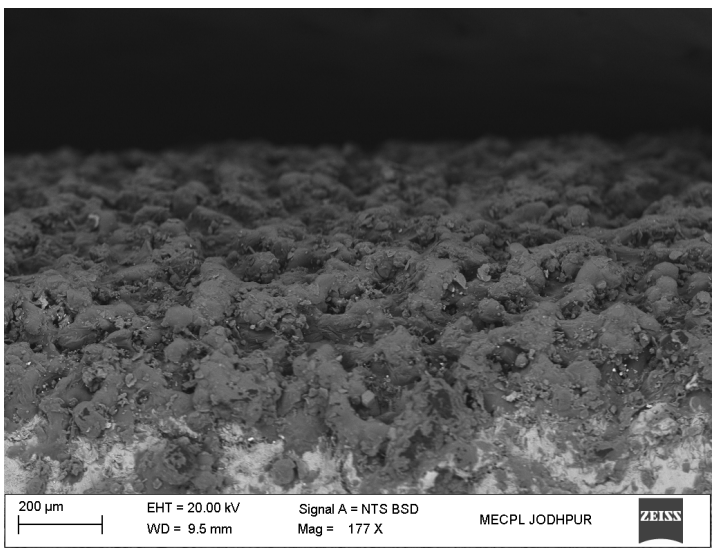

(d) 


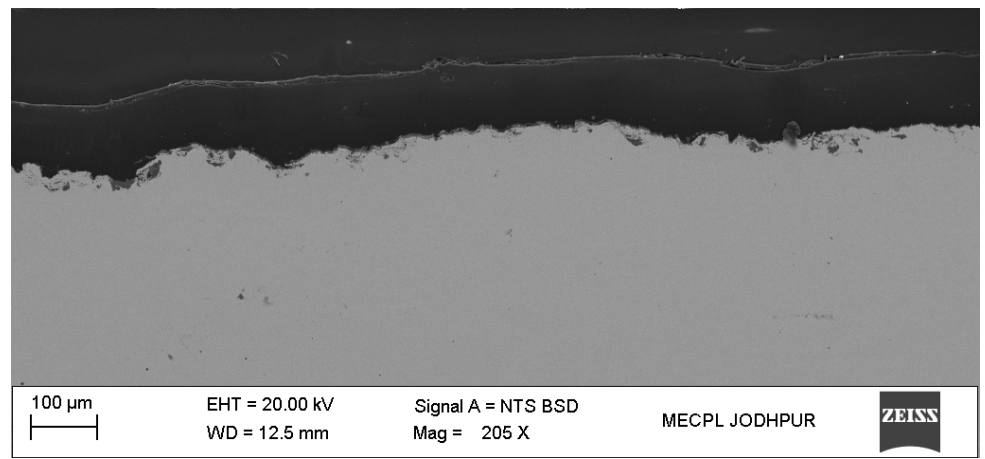

(e)

Figure 1: SEM images of porous PEEK coating, (a) cross section, (b-c) As-sprayed top surface,

(d) a tilt view of top surface, (e) dense PEEK coating

Table 2: Porous PEEK Pore Morphometrics

\begin{tabular}{|c|c|c|c|c|c|c|}
\hline $\begin{array}{l}\text { Morphometrics } \\
\text { properties }\end{array}$ & $\begin{array}{c}\text { Porosity } \\
(\%)\end{array}$ & $\begin{array}{c}\text { Pore Size } \\
(\mu \mathrm{m})\end{array}$ & $\begin{array}{c}\text { Strut Spacing } \\
(\mu \mathrm{m})\end{array}$ & $\begin{array}{c}\text { Strut } \\
\text { Thickness } \\
(\mu \mathrm{m})\end{array}$ & $\begin{array}{l}\text { Pore depth } \\
(\mu \mathrm{m})\end{array}$ & $\begin{array}{c}\text { Inter connectivity } \\
(\%)\end{array}$ \\
\hline Porous PEEK & $65.8 \pm 0.5$ & 30 to $80 \pm 10$ & $200 \pm 3$ & $100 \pm 3$ & $450 \pm 20$ & $97.93 \pm 0.01 \%$ \\
\hline
\end{tabular}

Quantitative $\mu \mathrm{CT}$ analysis of porous PEEK surfaces demonstrated similar pore morphology to previous reports $[23-24,27]$. Porous PEEK structures possessed a porosity of $65.8 \pm 0.5 \%$, pore size of 30 to $80 \pm 8 \mu \mathrm{m}$, strut spacing of $200 \pm 3 \mu \mathrm{m}$, strut thickness of $100 \pm 3 \mu \mathrm{m}$, pore depth of $450 \pm 20 \mu \mathrm{m}$, and interconnectivity of $97.93 \pm 0.01 \%$ (Table 2).

A numerous experiments were performed to obtain a porosity level up to $60-70 \%$. Figure 2 is represents the number of experiments in respect to achieved porosity in the coating. However, it is very difficult to deposit a polymer coating by thermal spray process due to higher temperature of the flame produces in thermal spraying. Polymer powder burns in high temperature flame during the deposition and it turns into carbon. Addressing this problem, a new thermal spray apparatus is designed and developed in MEC R\&D laboratory by employing a new spray nozzle. The new designed spray nozzle has a unique design which reduces flame temperature near about melting point of a polymer powder. This new spray nozzle is the result of many R\&D and design trails. After successful development of the spray nozzle at first controlled spray parameters were optimized for a dense PEEK coating (Fig. $1 \mathrm{e})$. And then, the controlled process parameters were optimized in order to get $60-70 \%$ porosity in as-sprayed PEEK coatings.

The microhardness measurement was carried out on polished cross-section of the as-sprayed coatings. The average of 15 identical hardness readings is taken along the cross-section of each sample. It was observed that porous PEEK coating has a considerable hardness and found to be $17 \pm 5$ HV.1; due to presence of high porosity.

Adhesion strength is an important factor in thermal spray coatings as well as in bio-implant applications because it is directly related to the performance and durability of the coating as it directly influences the fatigue life of the coating. Three point bend test was performed to check delamination characteristics of porous PEEK coatings and it was considered as a test to check the adhesion strength of the coating. Test showed that coating exhibited good bond strength. In addition tensile strength of the coatings was also investigated by the tensile test using INSTRON Digital Tensile Bond Testing Machine (UTM, Model: 5969, USA) and portable Pull-Off strength adhesion test (PosiTest ${ }^{\circledR}$ Pull-Off adhesion Tester). From these both tests the adhesion strength of the as-sprayed porous PEEK coatings was found to be $14 \pm 5.0 \mathrm{MPa}$, and $15 \pm 3.0 \mathrm{MPa}$ respectively.

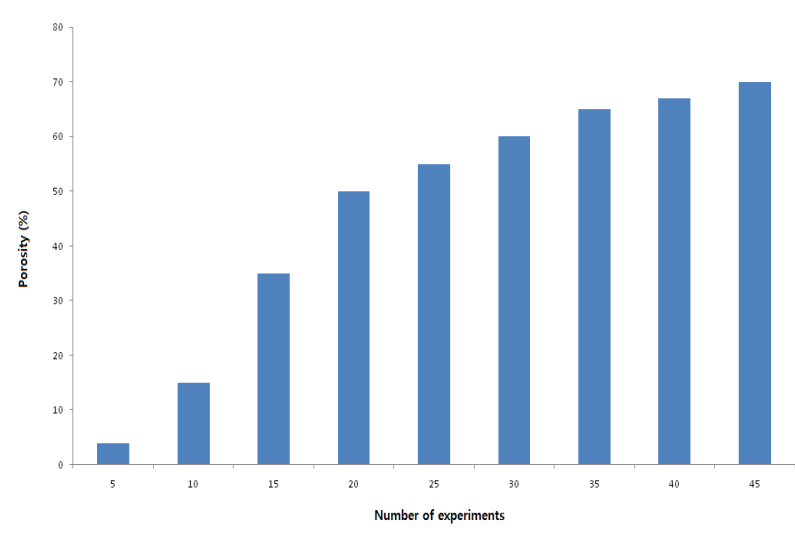

Figure 2: Porosity \% Vs Experiments conducted

Mechanical interlocking between the bone tissues and an implant is subjected to the implant surface characteristics such as size and relative position of both surfaces. Load bearing capacity of bone/ implant joint relies upon the bone ingrowth volume area [28]. Generally, the change in surface features by grit blasting, polishing, plasma spraying and texturing led to alter the bonding strength of titanium surface with bone material [4, 29]. A better mechanical bonding between the porous PEEK and bone in comparison 
to titanium deposited PEEK surface and bone implant was reported due to increased ingrowth volume of bone into porous PEEK [20]. Interlocking of bone and an implant mainly depends on large scale surface features rather than that of nano scale surface features. Insignificant fixation strength was showed by the nano scale surface features than large scale surface features on titanium surface [30]. Fixation strength of implant is also governed by the orientations of surface features along with the load i.e. shear or tensile. The examples of shear loading at bone implant interface are screw type and dowel pin while hip stems and spinal fusion subjected to the tensile loading [31]. Implant asperity intrusion and their engagement with asperous surfaces could withstand up to a degree. But in tensile loading, surface features such as porosity (undercutting) efficaciously unite with the bone. Inferior undercutting surface characteristics of titanium deposited PEEK caused to lower fixation strength under tensile loading in contrast to porous PEEK [20]. Osteoconduction created bonding between bone and implant also confer the fixation of implant, along with the mechanical interlocking. Implant fixation strength of bone with polished titanium surface was measured around $0.01 \mathrm{MPa}$ [32]. However, a standard tensile strength at bone implant interface ranged from 2-30 MPa depends upon the surface features and bone ingrowth mechanisms [4, 29, 32-33]. Bone-implant fixation phenomenon assumed to be mechanical yoking which is supported by micro surface features on implant surfaces [34].

Compressive strength of porous PEEK coating is shown in Fig. 3. Compressive strength of human trabecular bone is around $15 \mathrm{MPa}$ [35] with less deformation whereas porous PEEK coating structure demonstrate the required strength, but at higher deformations.

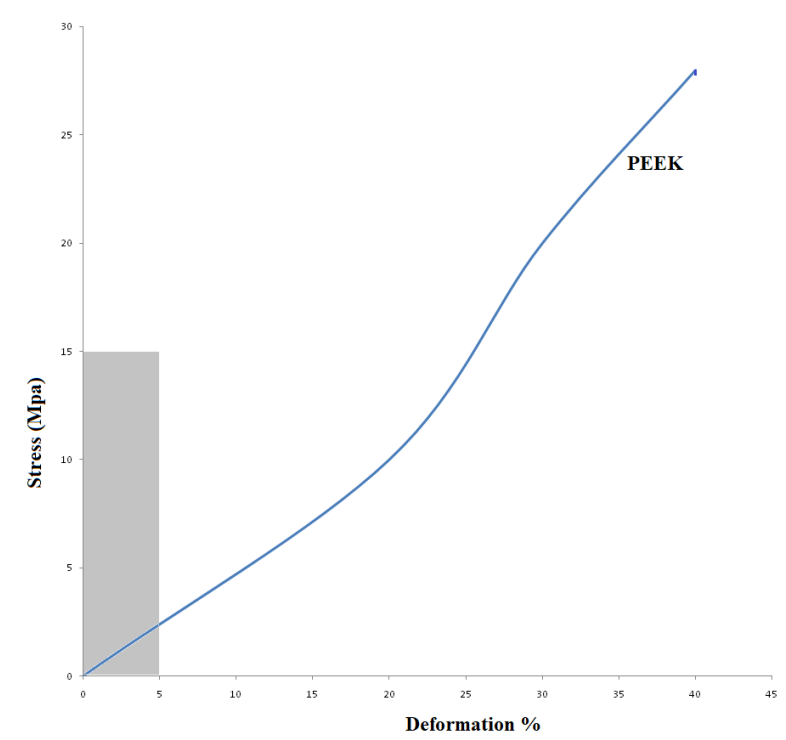

Figure 3: Stress-deformation diagrams for porous PEEK coating

\section{Conclusions}

Dense as well as porous PEEK coatings are fabricated by means of thermal spray process. This study reports new results and achievements in the fabricating of tailored porous PEEK coating for future bone implants. The developed coating exhibited a porous structure and good mechanical properties. Thermal sprayed porous PEEK coating could be a replacement of porous HAP coating on $\mathrm{Ti}$ implants and porous Ti coating on PEEK implants in biomedical implant industries. Better interlocking in porous PEEK, makes it promising and suitable for biomedical implants.

\section{References}

1. Kurtz SM. PEEK Biomaterials Handbook: William Andrew Publishing; 2012.

2. Kurtz SM. UHMWPE Biomaterials Handbook (Third Edition): William Andrew Publishing; 2016.

3. Kurtz SM, Devine JN. PEEK biomaterials in trauma, orthopedic, and spinal implants. Biomaterials. 2007; 28(32): 4845-69.

4. Walsh WR, Bertollo N, Christou C, Schaffner D, Mobbs RJ. Plasma-sprayed titanium coating to polyetheretherketone improves the bone-implant interface. Spine. 2015; 15(5): 1041-9.

5. Nieminen T., Kallela I., Wuolijoki E., Kainulainen H., Hiidenheimo I., Rantala I. Amorphous and crystalline polyetheretherketone: Mechanical properties and tissue reactions during a 3-year follow-up. J Biom Mat Res Part A. 2008; 84A(2): 377-383.

6. Jockisch K.A., Brown S.A., Bauer T.W., Merritt K.. Biological response to chopped-carbon-fiber-reinforced peek. J Biom Mat Res. 1992; 26(2): 133-146.

7. Devine D.M., Hahn J., Richards R.G., Gruner H., Wieling R., Pearce S.G. Coating of carbon fiber- reinforced polyetheretherketone implants with titanium to improve bone apposition. J Biomed Mater Res B Appl Biomater. 2013; 101(4): 591-8.

8. Wennerberg A., Albrektsson T., Andersson B. An animal study of $\mathrm{cp}$ titanium screws with different surface topographies. J Mat Sci-Mat in Medicine. 1995; 6(5): 302309.

9. Cheng A., Humayun A., Boyan B.D., Schwartz Z. Enhanced Osteoblast Response to Porosity and Resolution of Additively Manufactured Ti-6Al-4V Constructs with Trabeculae-Inspired Porosity. 3D Printing and Additive Manufacturing. 2016; 3(1): 10-21.

10. Boyan B.D., Bonewald L.F., Paschalis E.P., Lohmann C.H., Rosser J., Cochran D.L., Dean D.D., Schwartz Z., Boskey A.L. Osteoblast-mediated mineral deposition in culture is dependent on surface microtopography. Calcified Tissue International. 2002; 71(6): 519-529.

11. Van der Stok J., Van der Jagt O.P., Amin Yavari S., De Haas M.F., Waarsing J.H., Jahr H., Van Lieshout E.M., Patka P., Verhaar J.A., Zadpoor A.A., Weinans H. Selective laser melting-produced porous titanium scaffolds regenerate bone in critical size cortical bone defects. J Orthop Res. 2013; 31(5): 792-9

12. Vasconcellos L.M.R., Leite D.O., Oliveira F.N.d., Carvalho Y.R., Cairo C.A.A. Evaluation of bone ingrowth into porous titanium implant: histomorphometric analysis in rabbits. Brazilian Oral Research. 2010; 24: 399-405.

13. Wennerberg A., Albrektsson T. Effects of titanium surface topography on bone integration: a systematic review. Clinical Oral Implants Research. 2009; 20: 172-184.

14. Olivares-Navarrete R., Hyzy S.L., Slosar P.J., Schneider J.M., Schwartz Z., Boyan B.D. Implant Materials Generate Different Peri-implant Inflammatory Factors. Spine. 2015; 40(6): 399-404.

15. Vercaigne S., Wolke J.G., Naert I., Jansen J.A. Histomorphometrical and mechanical evaluation of titanium plasma-spray-coated implants placed in the cortical bone of goats. J Biomed Mater Res. 1998; 41(1): 41-8.

16. Franchi M., Bacchelli B., Martini D., Pasquale V.D., Orsini E., Ottani V., Fini M., Giavaresi G., Giardino R., Ruggeri A. Early detachment of titanium particles from various different surfaces of end osseous dental implants. Biomaterials. 2004; 25(12): 2239-46.

17. Kienle A., Graf N., Wilke H.J. Does impaction of titaniumcoated inter body fusion cages into the disc space cause 
wear debris or delamination? The Spine Journal. 2016; 16(2): 235-242.

18. Roybal R. Subtractive versus Additive Manufacturing of Spinal Implants. Paper presented at: 11th Annual Castellvi Spine Meeting. 2016; Duck Key, FL.

19. Torstrick F.B., Klosterhoff B.S., Westerlund L.E., Foley K.T., Gochuico J., Lee C.S.D., Gall K., Safranski D.L. Impaction durability of porous PEEK and titanium-coated PEEK interbody fusion devices. Spine J. 2018; 18(5): 857-865.

20. Brennan Torstrick F., Lin Angela S.P., Potter D, Safranski DL., Sulchek Todd A., Gall K, Guldberg Robert E. Porous PEEK improves the bone implant interface compared to plasma-sprayed titanium coating on PEEK. Biomaterials. 2018; 185: 106-116.

21. Senatov F.S., Niaza K.V., Salimon A.I., Maksimkin A.V., Kaloshkin S.D. Architected UHMWPE simulating trabecular bone tissue. Materials Today Communications. 2018; 14: 124-127.

22. Maksimkin A.V., Senatov F.S., Anisimova N.Yu., Kiselevskiy M.V., Zalepugin D.Yu., Chernyshova I.V., Tilkunova N.A., Kaloshkin S.D. Multilayer porous UHMWPE scaffolds for bone defects replacement. Materials Science and Engineering: C. 2017; 73: 366-372.

23. Torstrick F.B., Safranski D.L., Burkus J.K., Chappuis J.L., Guldberg R.E., Smith K.E. Getting PEEK to Stick to Bone: The Development of Porous PEEK for Interbody Fusion Devices. Tech Orthop. 2017; 32(3): 158-166.

24. Torstrick F.B., Evans N.T., Stevens H.Y., Gall K., Guldberg R.E. Do Surface Porosity and Pore Size Influence Mechanical Properties and Cellular Response to PEEK? Clin. Orthop. Relat. R. 2016; 474: 2373- 2383.

25. Evans N.T., Torstrick F.B., Safranski D.L., Guldberg R.E. Gall K. Local deformation behavior of surface porous polyether-ether-ketone. J Mech Behav Biomed Mater. 2017; 65: 522-532.

26. Evans N.T., Torstrick F.B., Lee C.S., Dupont K.M., Safranski D.L., Chang W.A., Macedo A.E., Lin A.S., Boothby J.M., Whittingslow D.C., Carson R.A., Guldberg R.E., Gall K. Highstrength, surface-porous polyether-ether-ketone for loadbearing orthopedic implants. Acta Biomater. 2015; 13: 159-67.

27. N.T. Evans, F.B. Torstrick, C.S. Lee, K.M. Dupont, D.L. Safranski, W.A. Chang, A.E. Macedo, A.S. Lin, J.M. Boothby, D.C. Whittingslow, R.A. Carson, R.E. Guldberg, K. Gall, Highstrength, surface-porous polyether-ether-ketone for loadbearing orthopedic implants, Acta Biomater 13 (2015) 159-67.

28. Yakacki C.M., Griffis J., Poukalova M., Gall K. Bearing area: A new indication for suture anchor pullout strength? J Orthopaedic Research. 2009; 27(8): 1048-1054.

29. Svehla M., Morberg P., Zicat B., Bruce W., Sonnabend D., Walsh W.R. Morphometric and mechanical evaluation of titanium implant integration: comparison of five surface structures. J Biomed Mater Res. 2000; 51(1): 15-22.

30. Wang X., Schwartz Z., Gittens R.A., Cheng A., OlivaresNavarrete R., Chen H., Boyan B.D. Role of integrin alpha(2)beta(1) in mediating osteoblastic differentiation on three-dimensional titanium scaffolds with submicronscale texture. Journal of Biomedical Materials Research Part A. 2015; 103(6): 1907-1918.

31. Bobyn J.D., Pilliar R.M., Cameron H.U., Weatherly G.C., Kent G.M. The effect of porous surface configuration on the tensile strength of fixation of implants by bone ingrowth. Clin Orthop Relat Res. 1980; 149: 291-8.

32. Skripitz R., Aspenberg P. Tensile bond between bone and titanium: a reappraisal of osseointegration. Acta orthopaedica Scandinavica. 1998; 69(3): 315-9.

33. Clemow A.J., Weinstein A.M., Klawitter J.J., Koeneman J., Anderson J. Interface mechanics of porous titanium implants. J Biomed Mater Res. 1981; 15(1): 73-82.

34. Davies J.E. Bone bonding at natural and biomaterial surfaces. Biomaterials. 2007; 28(34): 5058-67.
35. D. W. Sommerfeldt and C T Rubin. "Biology of bone and how it orchestrates the form and function of the skeleton". Eur Spine J (2001), 10 (2), S86-S95. 